\title{
A comparative meta-analysis of membraneless organelle associated proteins with age related proteome of C. elegans
}

Pritam Mukherjee ${ }^{1,2}$, Prajnadipta Panda ${ }^{1,2}$ and Prasad Kasturi ${ }^{1,2, ~ *}$

${ }^{1}$ BioX centre, ${ }^{2}$ School of Basic Sciences, Indian Institute of Technology Mandi Kamand, Himachal Pradesh - 175005, India

*Corresponding author: prasadkasturi@iitmandi.ac.in

Prasad Kasturi

ORCID ID: 0000-0002-3611-5489

Pritam Mukherjee

ORCID ID: 0000-0003-0355-0422

Prajnadipta Panda

ORCID ID: 0000-0001-7528-4448 


\section{ABSTRACT}

Proteome imbalance can lead to protein misfolding and aggregation which is associated with pathologies. Protein aggregation can also be an active, organized process and can be exploited by cells as a survival strategy. In adverse conditions, it is beneficial to deposit the proteins in a condensate rather degrading and resynthesizing. Membrane less organelles (MLOs) are biological condensates formed through liquid-liquid phase separation (LLPS), involving cellular components such as nucleic acids and proteins. LLPS is a regulated process, which when perturbed, can undergo a transition from a physiological liquid condensate to pathological solid-like protein aggregates.

To understand how the MLO-associated proteins (MLO-APs) behave during aging, we performed a comparative meta-analysis with age related proteome of $C$. elegans. We found that the MLO-APs are highly abundant throughout the lifespan. Interestingly, they are aggregating more in long-lived mutant worms compared to the age matched wildtype worms. GO term analysis revealed that the cell cycle and embryonic development are among the top enriched processes in addition to RNA metabolism RNP components. Considering antagonistic pleotropic nature of these developmental genes and post mitotic status of $C$. elegans, we assume that these proteins phase transit during post development. As the organism ages, these MLO-APs either mature to become more insoluble or dissolve in uncontrolled manner. However, in the long-lived daf-2 mutant worms, the MLOs may attain protective states due to enhanced proteostasis components and altered metabolism that eventually make these worms more protected. 


\section{INTRODUCTION}

Aging is a major risk factor for many diseases, including neurodegenerative, diabetes, cancer, and cardiovascular diseases (Hou et al., 2019). A major pathological hallmark of most of these disorders is protein misfolding and subsequent aggregation (Ross and Poirier, 2004) due to compromised protein homeostasis (proteostasis) (Hartl 2016). Proteostasis refers to the maintenance of the proteome in the correct conformation, concentration, and location required for cellular functions (Balch et al., 2008; Labbadia and Morimoto, 2015; Verma et al., 2021). Stress response and longevity pathways also promote proteostasis. For example, heat shock proteins (molecular chaperones) are expressed under various stress conditions to protect the proteome. They are targets of the conserved stress response pathways such as HSR (heat shock response) and IIS (insulin/IGF1-like signalling pathway) that affect proteostasis and life span (Hsu et al., 2003; Klaips et al., 2018). Indeed, it has been reported that long lived daf-2 (insulin like receptor) mutant $C$. elegans activate a protective aggregation response during aging to maintain extended proteostasis (Walther et al., 2015). In part, this is achieved by inducing small heat shock proteins (sHSPs) expression, which in turn reduce the burden of misfolding proteins by sequestering them to aggregates or condensates. Notably, it has been observed that highly abundant proteins contribute more to the aggregate load due to their exceeding levels of solubility (super saturation). These supersaturated proteins form a metastable sub-proteome and undergo aggregation or interact with aggregates during stress or aging. Supersaturation of the proteins is one of the driving forces for the increased protein aggregation (Ciryam et al., 2013, 2015, 2019; Walther et al., 2015).

Protein aggregates are considered inherently irreversible aberrant clumps, and are often associated with pathologies (Hipp et al., 2014; Soto and Pritzkow, 2018). However, recent evidence demonstrates that protein aggregation can also be an active, organized process (Fassler et al., 2021; Miller at al., 2015; Boronat et al., 2021). Physiological and reversible protein aggregation which seem to be beneficial has been observed in diverse systems from yeast to mammalian cells (Wallace et al., 2015; Saad et al., 2017; Becker and Gitler 2018; Cereghetti et al, 2021). Regulated and often reversible formation of protein aggregates or condensates perform a wide variety of cellular functions including response to stress, gene expression, cellular development and differentiation etc. (Alberti and Hyman., 2021; Fassler et al., 2021).

Recently, it has been demonstrated that under diverse conditions biological molecules can demix or remix (phase separation) with surrounding media. This phase separation in cells creates biomolecular condensate or membraneless organelles (MLOs) that can provide 
organization centre for biochemical reactions (Alberti, 2017; Boeynaems et al., 2018). Liquidliquid phase-separation (LLPS) is a reversible molecular process that promotes the formation of biomolecular condensates or MLOs in living cells by proteins and RNA molecules, which have no fixed stoichiometry (Shin and Brangwynne 2017). For example, stress granules (SGs) are highly dynamic condensates formed in response to stress. These condensates are composed of two types of molecules, scaffolds and clients. While scaffold molecules have high number of valences and necessary for condensate formation, the client molecules have lower interaction valences and are recruited to condensates and can function as regulators. These phase-separated and reversible assemblies provide a general regulatory mechanism as part of the stress response (Riback et al., 2017; Franzmann and Alberti 2019). In some situations, liquid to gel-like transition is essential cellular functions (Putnam et al., 2019; Bose et al., 2021). However, when this process is dysregulated, some condensates mature into non-dynamic, gel to solid like condensates, which are more toxic (Alberti and Carra 2018). These aberrant phase-transitions, might result in irreversible damage that acts as drivers of cellular aging (Alberti and Hyman 2016). It has been reported that the age dependent aggregated proteins have a significantly higher propensity for LLPS. Likewise, many supersaturated proteins also form condensates by phase separation (Vecchi et al., 2020).

Organisms might utilize this fundamental mechanism of LLPS to cost-efficiently organize and reorganize cellular resources according to functional needs, especially during stress and aging (Franzmann and Alberti 2019; Alberti and Hyman., 2021). However, it is not yet clear how the cells select which form of condensates is preferred and beneficial for long term storage of biomolecules, and what regulates and maintains that preferred state of condensates from aberrant transitions. In an attempt to understand this, we choose to address the question of how the proteins capable of undergoing LLPS behave during aging and if aggregation of these proteins plays any cyto-protective roles by sequestration-based strategies. To do this, we obtained C. elegans MLO-APs from MLOS-MetaDb database (Orti et al., 2021) and investigated their behaviour during aging by comparing age associated proteomes of wildtype (WT) and long lived daf-2 mutant worms as well as gonad less mutants (Walther et al., 2015; David et al., 2010). Our analysis revealed that proteins involved in cell cycle and embryonic development are also among the MLO-APs. Majority of the MLO-APs maintain their higher abundance levels during the life span and sequester to aggregates or condensates. As the organism ages, these MLOs either mature to become more insoluble or dissolve in uncontrolled manner. However, in the long-lived daf-2 mutant worms, the MLOs may attain different protective states due to enhanced proteostasis. 


\section{RESULTS \& DISCUSSION}

\section{Functional annotations of membraneless organelle associated proteins (MLO-APs)}

Membraneless organelles or biomolecular condensates are intracellular assemblies without surrounding a membrane that often form via liquid-liquid phase separation (LLPS). They have the ability to concentrate biomolecules and polymers to provide a spatial organization for biochemical reactions (Banani et al., 2017). Since condensates play key roles in cellular organization and physiology, their assembly and dissolution must be tightly controlled. Failure to control this regulation can result severe defects from development to aging and can lead to diseases associated with protein aggregation. To better understand the proteins that form biological condensates or MLOs, their function and regulation, we sought to identify their functional categories. For this, we downloaded known and predicted C. elegans specific MLOs associated proteins (MLO-APS) from MLOS-MetaDb, a meta server for membraneless organelles associated proteins (Orti et al., 2021). This dataset consists of consolidated set of 413 proteins entries from three databases: PhaSePro (Mészáros et al., 2020), PhasepDB (You et al., 2020), DrLLPS (Ning et al., 2020] (Table-1). We then looked for their biological processes by GO term analyses in Metascape (Zhou et al., 2019). All the C. elegans protein coding genes were considered for the background. In biological process category, we found that cell cycle (GO:0007049), translation (GO:0006412), embryo development (GO: 0009790), multi-organism reproductive process (GO:0044703), ribonucleoprotein complex biogenesis (GO: 0022613) were among the top enriched terms (Figure 1A).

Since these proteins are predicted to undergo LLPS, we checked their association with any known MLOs, by looking into the MLO count bar graph in the database. We found that most of these proteins are unannotated with any known MLO, then followed by $P$ body, stress granule, nucleolus and PML (promyelocytic leukemia) nuclear body. By doing GO cellular component analysis, we found the top enrichment in P granule (GO:0043186) followed by ribonucleoprotein (RNP) complex (GO: 1990904), microtubule cytoskeleton (GO:0015630), nucleolus (GO:0005730) (Figure 1B). We also checked the protein-protein interaction (PPI) network enrichment in Metascape, and found 16 Molecular Complex Detection (MCODE) networks (Figure 1C). The algorithm also provided the meanings by GO terms. We found the PPI enrichments for P-granule, m-RNP components, ribosomal subunit associated, proteasome, nucleolus, nuclear pore complex (NPC) and Chaperonin containing tailless complex polypeptide 1 (CCT) or tailless complex polypeptide 1 ring complex (TRiC). Interestingly we also found PPI enrichment of processes like cell cycle and developmental events. The network components and meanings are summarized in Table-2. 
These results confirms that the analysed MLO-APs are components of known biomolecular condensates such as stress granules, p-bodies and nucleolus. These MLO-APs are also involved in diverse cellular functions from RNA metabolism to protein quality control (PQC). In addition, they also highlight importance of MLOs in cytoskeletal organization (Wiegand et al., 2020) as well as roles for biomolecular condensates during cell division (Ong and Torres 2020). From this analysis, we assume that while some of these MLO-APs could act as scaffolds, majority of them are client and/or regulator molecules.

\section{Age associated behaviour of MLO associated proteins}

Protein misfolding and aggregation are hallmarks of many age-related diseases including neurodegeneration (Soto and Pritzkow, 2018; Hou et al., 2019). Protein aggregation not only increases with age but also contributes to it (David et al., 2010; Walther et al., 2015; Huang et al., 2019). When protein abundances or concentrations exceed their solubility levels, they become supersaturated and form a metastable sub-proteome that undergo aggregation or interact with aggregates during stress or aging. Supersaturation of the proteins is one of the driving forces for this increased protein aggregation in human tissues and $C$. elegans (Ciryam et al., 2013, 2015, 2019; Walther et al., 2015). Supersaturated proteins can also form condensates by LLPS. Aggregation-prone proteins are observed to be accumulated in the condensates and promote their hardening, indicating that both protein aggregation and condensation are probably linked. In fact, there is a link between condensate-forming proteins and ageing-related diseases such as neurodegeneration (Alberti and Dormann 2019). Age dependent decline in proteostasis contribute to the accumulation of misfolding proteins and also formation of aberrant, disease-causing condensates. However, there is compelling evidence that aging organism try to maintain their proteome balance by activating a proteomescale protective aggregation response during aging. This protective response is more pronounced in long lived daf-2 mutants compared to wildtype worms (Walther et al., 2015). Sequestering of toxic molecules in biomolecular condensates or MLOs is one such protective response during aging which might be enhanced in long lived organism

To explore behaviour of the MLO-APs during aging, we investigated their abundance levels and aggregation by using published age-related proteomic dataset from wildtype and daf-2 mutant worms (Walther et al., 2015). First, we looked for the abundance profiles of the MLOAPs that we analysed above. In total, 364 MLO-APs are identified in the aging proteome (Table-3), however only 289 proteins are quantified in all the time points in the total proteome of both wildtype and daf-2 mutant worms. These proteins are among the highly abundant proteins from day 1 of adulthood and maintain their higher abundance throughout the lifespan 
(Figure $2 \mathrm{~A}$ and $2 \mathrm{~B}$ ). Although they are among the highly abundant proteins, they are differentially expressed in wildtype and daf-2 mutants as is evident from the heat map (Figure 2B). Interestingly, we observed that the granule forming propensity [catGRANULE] scores (Bolognesi et al., 2016) of these proteins do not correlate with their abundance intensities, that is the MLO-APs with highest granule forming propensity scores does not necessarily have highest LFQ intensity during aging (data not shown). It is unclear if the higher abundances of these MLO associated proteins are enough for them to undergo LLPS and form condensates, as their experimentally determined critical concentrations are not known. This suggest that intracellular milieu is the driving force for LLPS and condensate formation.

Membraneless organelles or biomolecular condensates are generally liquid like state, however with time they become more solid like. Although proteins associated stress granules become detergent insoluble with age (Lechler et al., 2017), it is unknown for other MLO-Aps. Here we report that the 364 MLO-APs (quantified in all time points) that are identified in aggregated proteome in wildtype and daf-2 mutant worms are weak detergent insoluble. We found that the aggregation of these proteins increases after day 6 of adulthood as reported earlier (Walther et al., 2015) (Figure 2C and 2D). Our analysis shows that in wildtype worms out of 364 MLO-APs, 112 proteins are significantly upregulated and 10 proteins are downregulated in the day12 aggregates (Figure 2E, Table-4). Interestingly, the daf-2 mutant worms contain more aggregation load compared to wildtype worms when considering common MLO-APs at day12 insoluble aggregated proteome (Figure 2F). Notably the upregulated insoluble proteins are enriched for the cell cycle (GO:0007049), gamete generation (GO:0007276), embryo development (GO: 0009790) regulation of protein metabolic process (GO: 0051246), cytokinesis (GO:0000910) and DNA replication (GO:0006260) (Figure 2G). Given the protective aggregation response of daf-2 mutant worms (by increasing SHSPs levels) and altered metabolism, we assume active reorganization of biological condensates including sequestration of other toxic / harmful molecules.

It has been observed that the highly abundant proteins are generally more soluble and have low intrinsic aggregation-propensities. During aging, a subset of high abundance proteins become supersaturated resulting in their aggregation or phase transits in case of condensates. In contrast, it has been reported that intrinsically aggregation-prone proteins form amyloid-like aggregates and contribute to aging (Huang et al., 2019).

We then turned our attention to the analysis of proteins that are likely to become susceptible to aggregation when the control of protein homeostasis declines as in aging. An interesting observation that the proteins associated with embryonic development and cell cycle are 
among the significantly enriched in aggregates, compelled us to check if there is a commonality in wildtype and daf-2 mutant worms aging associated sequestering of proteins in aggregates that functions in similar biological process. To answer this, we considered common proteins that have been quantified (at all the time points) in total and aggregate proteome of wildtype and daf-2 mutant worms (wildtype Total - 307, daf-2 Total - 298, wildtype aggregates - 210, daf-2 aggregates - 170; Table-5 and 6). We then performed GO term analysis and found that the enrichments of processes and cellular components are similar in both wildtype and daf-2 mutant worms (Figure 3A and 3B). The following are among the top enriched terms for the proteins identified in aggregates. Translation (GO:0006412), cell cycle (GO:0007049), embryo development (GO:0009790) and embryo development ending in birth or egg hatching (GO:0009792) and DNA unwinding involved in DNA replication (GO:0006268).

Why these cell cycle and developmental proteins are more enriched in the insoluble fractions? Why they are not removed post development or in post mitotic tissues? In their review, Fassler et al (2021) explained that condensates and amyloid aggregates are present in germline and developing embryos and are a normal aspect of physiological functions and development. Since abundance of these proteins increase during aging and exceed their solubility levels (supersaturated) result in forming condensates that are different from developmental condensates. They might also attain different fates depending the cellular environment and condition. We favour that in daf-2 mutant worms they function as beneficial repositor for sequestering surplus proteins for an extended duration compared to the wildtype worms.

\section{Aggregation of MLO associated proteins as a protective strategy}

To get more insight on cell cycle and developmental proteins during aging and also roles for $P Q C$ machinery in maintaining biological condensates, we investigated changes in these components during lifespan in wildtype and long lived daf-2 mutant worms. As explained above the proteins associated with cell cycle and embryonic development are among the significantly enriched in aggregates. This observation compelled us to check if there is a commonality associated with sequestering of proteins in aggregates that functions in similar biological process in wildtype and daf-2 mutant worms during aging.

We then systematically checked fates of these developmental, cell cycle (mitotic and meiotic) proteins as well as proteostasis components (Table-7) during aging in total and aggregated proteomes of wildtype and daf-2 mutant worms. 
First, we looked at cell cycle and developmental proteins. When compared to day1 total proteome, there is no change in the abundance levels in wildtype worms, but in daf-2 mutants there is a slight increase. However, when compared to age matched samples, there is clear increase in the daf-2 mutants (Figure 4A, C and E). When compared to day1 aggregated proteome, there is an increase in the aggregate abundance levels both in wildtype and daf-2 mutant worms (Figure 4B, D and F). These protein aggregates are more enriched in daf-2 mutant worms.

Embryonic developmental and cell cycle related protein are enriched in the germline (Pu et al., 2017; Turner et al., 2015), suggesting a possibility that aggregation of these proteins is contributed by the germline. in the germline. To rule out this possibility we checked other proteome data where worm strains lacking gonad or germline were used for proteome aggregation analysis during aging (David et al., 2010). We found that embryonic developmental proteins and DNA replication related proteins are also shown to be aggregating during aging. Since, we considered proteins that are associated with MLOs which are capable to undergo LLPS, we assume these proteins might be part of condensates or help in phase transitions.

Evolutionary theory of aging states that the developmental genes have antagonistic pleotropic nature. Their function is required during development; however, the same gene products might have negative consequences later in the age. Remarkably, it has been shown that reducing their levels by RNAi mediated knockdown during post developmental stages increases the life span wildtype as well as in daf-2 mutant worms (Curran and Ruvkun 2007; Chen et al., 2007).

Considering the nature of the analysed proteins as MLOs which can phase-separate, we assume two possible roles for these proteins getting sequestrated to aggregates or condensates during aging. First, during development these proteins might be sequestered to liquid like functional condensates, as the organism ages, these condensates become gradually phase-transit to more solid like condensates. Finding these proteins in the aging aggregate fractions suggest a protective strategy for cells to sequester them from the pool so that their antagonistic pleotropic effects are reduced. Second, aggregation of these proteins instead of degradation, further increase the burden on cellular proteostasis and may be the possible detrimental effects that these proteins offer. We assume the former case is true as the proteins required for developmental processes are also found to be aggregating during aging in worms with or without germline (Walther et al., 2015; David et al., 2010). In support of this, it has been described that condensation of the developmental proteins is required for physiological functions (Skuodas et al., 2020). 
Moreover, MLO-APs related to mitotic and meiotic cell cycle and proteins associated with DNA replication are also found to be sequestered in aggregates during aging. Major contribution is supposed to come from the oocytes and germ cells in the aging gonads. During aging the germline stem cells are reported to be quiescent, mitotic and meiotic processes comes to a halt and the proteins might not be properly distributed to the daughter cells. Thus, at that stage sequestering those proteins into aggregates or condensates but not degrading offer a protective strategy. If any divide signal is induced later in life (by sperm from a male), the proteins can readily be available for their function. It's worth noting that disturbing p-granule condensates in the germline lead to trans-differentiation of germ cells to somatic cells (Updike et al., 2014), suggesting that the condensate organization is tightly regulated process.

It has been reported that organisms such as $C$. elegans and Xenopus begin life with an appreciable amount of amyloid material. However, their disassembly may lead to functional defects including developmental arrest. Indeed, it has been shown that ectopic expression of HSP104 (yeast disaggregase) in C. elegans caused cell division defects and embryonic lethality (Skuodas et al., 2020). These findings suggest that amyloid aggregates are a normal aspect of physiological functions and development and that their proper regulation is essential (Fassler et al., 2021). We conclude that formation of condensate appears to be an ideal way to selectively deposit misfolding-prone and surplus proteins during development as well as stress and aging to reduce burden on the PQC system and also to maintain balanced proteome.

\section{PQC related components as modifiers of MLOs}

Decline or loss of proteostasis is one of the hallmarks of aging. Proper maintenance of proteostasis or the PQC machinery is essential for organismal survival and fitness especially during aging. Protein folding and degradation arms of the proteostasis, determine fate of the accumulating misfolding-prone proteins during aging either by sequestrating them into protective aggregates (or condensates) or eliminating them by degradation. Recent evidences suggest the extensive incorporation of proteostasis components into the dynamic assembly of MLOs, where different chaperones coordinate to spatiotemporally maintain the protein homeostasis and avoid abnormal protein aggregation. Molecular chaperones are also implicated in preventing the accumulation of misfolding proteins in condensates as well as in reversing the solid-like state of condensates (Mateju et a., 2017; Gu et al., 2020, 2021; Boczek et al., 2021; Lu et al., 2021), suggesting roles for PQC machinery in condensate quality maintenance. 
Since aberrant condensate formation or disassembly are linked to protein aggregation diseases, we wanted to analyse PQC related components in the MLO-APs and how differently they behave during aging in wildtype and long-lived mutant worms. From the MLOS-MetaDb, we found around 70 proteins as MLO-APs whose roles are ascertained to protein quality control including protein biogenesis, folding and degradation (Table-7). Our analysis revealed that these proteins are relatively downregulated compared to day1 in wildtype worms but are comparatively found more in aggregate fraction. However, in daf-2 mutant worms they are relatively upregulated compared to day 1 and also enriched more in the aggregates compared to its age matched wildtype counterparts (Figure $5 A$ and $B$ ). This again suggest existence of a protective response in daf-2 mutans worms.

There have been reports about HSPs to be involved in the quality control of biomolecular condensates (Li and Liu 2021). Therefore, we also looked separately on the cytosolic HSPs assuming they are also MLO-APs (which are not yet entered in MLOS-MetaDb dataset). We found that similar to other proteostasis component proteins, these HSPs are also upregulated in the total proteome daf-2 mutant worms compared to age matched wildtype worms. Likewise, these HSPs are also more strongly enriched in the aggregates of daf-2 mutant worms. Among the HSPs, small heat shock proteins (SHSPs) are reported to promote sequestration of protein aggregation. Having multi-valent binding ability, sHSPs may act to seed and accumulate aggregate material. Furthermore, sHSPs mediated sequestered proteins maintain their near native confirmations for efficient refolding (Ungelenk et al., 2016; Mogk and Bukau 2017). This suggest that SHSPs may also actively promote formation of biological condensates. The altered metabolism in daf-2 may further act as buffer in promoting SHSPs as promoters of aggregation or phase-transitions of condensates. Indeed, it has been shown that overexpression of sHSPs result in beneficial effects. To further support, it has been showed that depletion of DAF-2 protein only late in life also result in lifespan extension (Venz et al., 2021). This strongly support, roles for PQC components modulating biological condensates for beneficial effects especially during aging.

We conclude that during aging, the wildtype worms might sequester misfolding-prone proteins into condensates where the few MLO-APs act as scaffolds. However, with increasing age, these condensates due to insufficient PQC components, may aberrantly transit to toxic solids or abruptly dissolve their content. This leaking of the accumulated toxic molecular species might make inappropriate interactions with other molecules and eventually result in protostasis collapse. In contrast, daf-2 mutant worms efficiently maintain condensate organization by recruiting more MLO-APs including PQC components and other factors to prevent or slow down aberrant phase-transitions and dissolution of the condensates. This eventually minimize 
leakage of misfolding proteins and preventing their inappropriate interactions with other molecules, which in turn reduce the burden on the PQC machinery. However, these assumptions and observations need to experimentally verified or validated.

\section{METHODS}

\section{Data Collection}

Membraneless (MLOs) associated proteins were downloaded from the MLOS-MetaDb (Orti et al., 2021) for $C$. elegans model organism. While downloading the dataset we used the all the options from PhasepPro, PhasepDB-Low Throughput, PhasepDB-High Throughput, DrLLPSScaffolds, DrLLPS-High Throughput, DrLLPS- Regulators. The resulted in dataset consisting of 413 UniProt IDs with their LLPS associated characteristics (disorder content, LCRs, NLCRs as well as Sources, References).

Aging proteome of $C$. elegans was downloaded from the published dataset (Walther et al., 2015; David et al., 2010). Excel files containing age related changes in total and aggregate proteome of wildtype and daf-2 mutant strains from Walther et al., (2015) were extracted and used for main analysis. To check for the gonad and germline less effects on the aggregation of MLO-APs, data from David et al., (2010) was used.

\section{Data Analysis}

Proteome data was analysed using Perseus 1.6.15.0 (Tyanova et al., 2016), Microsoft Excel and GraphPad Prism software. We first annotated the identified proteins based on categorical annotation provided by MLOS-MetaDb. We then cleaned our dataset based on this categorical annotation. Metascape server was used for analysing gene ontology and PPI networks. Graph Pad Prism 9 and ggplot2 in R (Wickham 2016) was used for graphical representation of data.

\section{Datasets}

The datasets used in this work are available in the supplemental file.

\section{AUTHOR CONTRIBUTIONS}

P.M and P.K conceived the project. P.M performed analysis and made draft figures. P.M, P.P and P.K analysed the data and performed the figure visualizations. P.M and P.K wrote the manuscript. 


\section{ACKNOWLEDGMENTS}

This work was supported by DBT-Ramalingaswami Fellowship (DBT/RLF/RE-entry/31/2018 to PK) and by IIT Mandi seed grant (IITM/SG/PKS-78 to P.K). PM acknowledges Ministry of Education and IIT Mandi for HTRA fellowship assistance and PP acknowledges DST for INSPIRE fellowship. The authors acknowledge BioX centre, SBS at IIT Mandi for providing facilities.

\section{CONFLICTS OF INTEREST}

The authors declare no conflict of interest.

\section{REFERENCES}

Alberti S, Carra S. Quality Control of Membraneless Organelles. J Mol Biol. 2018 Nov 2;430(23):4711-4729.

Alberti S and Hyman AA. (2016). Are aberrant phase transitions a driver of cellular aging? Bioessays. 38(10):959-68.

Alberti S and Hyman AA. Biomolecular condensates at the nexus of cellular stress, protein aggregation disease and ageing. Nat Rev Mol Cell Biol. 2021 Mar;22(3):196-213.

Alberti S, Dormann D. Liquid-Liquid Phase Separation in Disease. Annu Rev Genet. 2019 Dec 3;53:171-194.

Alberti S. Phase separation in biology. Curr Biol. 2017 Oct 23;27(20):R1097-R1102.

Balch WE, Morimoto RI, Dillin A, Kelly JW. Adapting proteostasis for disease intervention. Science. 2008 Feb 15;319(5865):916-9.

Banani SF, Lee HO, Hyman AA, Rosen MK. Biomolecular condensates: organizers of cellular biochemistry. Nat Rev Mol Cell Biol. 2017 May;18(5):285-298.

Becker LA and Gitler AD. A neurodegenerative-disease protein forms beneficial aggregates in healthy muscle. Nature 2018 Nov;563(7732):477-478.

Boczek EE, Fürsch J, Niedermeier ML, Jawerth L, Jahnel M, Ruer-Gruß M, Kammer KM, Heid P, Mediani L, Wang J, Yan X, Pozniakovski A, Poser I, Mateju D, Hubatsch L, Carra S, Alberti S, Hyman AA, Stengel F. HspB8 prevents aberrant phase transitions of FUS by chaperoning its folded RNA-binding domain. Elife. 2021 Sep 6;10:e69377.

Boeynaems S, Alberti S, Fawzi NL, Mittag T, Polymenidou M, Rousseau F, Schymkowitz J, Shorter J, Wolozin B, Van Den Bosch L, Tompa P, Fuxreiter M. Protein Phase Separation: A New Phase in Cell Biology. Trends Cell Biol. 2018 Jun;28(6):420-435.

Bolognesi B, Lorenzo Gotor N, Dhar R, Cirillo D, Baldrighi M, Tartaglia GG, Lehner B. A Concentration-Dependent Liquid Phase Separation Can Cause Toxicity upon Increased Protein Expression. Cell Rep. 2016 Jun 28;16(1):222-231.

Boronat S, Cabrera M, Hidalgo E. Spatial sequestration of misfolded proteins as an active chaperone-mediated process during heat stress. Curr Genet. 2021 Apr;67(2):237-243. 
Bose M, Mahamid J, Ephrussi A. Liquid-to-solid phase transition of oskar RNP granules is essential for their function in the Drosophila germline. BioRxiv 2021. doi: https://doi.org/10.1101/2021.03.31.437848

Cereghetti G, Wilson-Zbinden C, Kissling VM, Diether M, Arm A, Yoo H, Piazza I, Saad S, Picotti P, Drummond DA, Sauer U, Dechant R, Peter M. Reversible amyloids of pyruvate kinase couple cell metabolism and stress granule disassembly. Nat Cell Biol. 2021 Oct;23(10):1085-1094.

Chen D, Pan KZ, Palter JE, Kapahi P. Longevity determined by developmental arrest genes in Caenorhabditis elegans. Aging Cell. 2007 Aug; 6(4): 525-533.

Ciryam P, Tartaglia GG, Morimoto RI, Dobson CM, Vendruscolo M. Widespread aggregation and neurodegenerative diseases are associated with supersaturated proteins. Cell Rep. 2013 Nov 14;5(3):781-90.

Ciryam P, Kundra R, Morimoto RI, Dobson CM, Vendruscolo M. Supersaturation is a major driving force for protein aggregation in neurodegenerative diseases.Trends Pharmacol Sci. 2015 Feb;36(2):72-7.

Ciryam P, Antalek M, Cid F, Tartaglia GG, Dobson CM, Guettsches AK, Eggers B, Vorgerd M, Marcus K, Kley RA, Morimoto RI, Vendruscolo M, Weihl CC. A metastable subproteome underlies inclusion formation in muscle proteinopathies. Acta Neuropathol Commun. 2019 Dec 3;7(1):197.

Curran SP, Ruvkun G. Lifespan regulation by evolutionarily conserved genes essential for viability. PLoS Genet. 2007 Apr 6;3(4):e56.

David DC, Ollikainen N, Trinidad JC, Cary MP, Burlingame AL, Kenyon C. Widespread protein aggregation as an inherent part of aging in C. elegans. PLoS Biol. 2010 Aug 10;8(8):e1000450.

Fassler JS, Skuodas S, Week DL, Phillips BT. Protein Aggregation and Disaggregation in Cells and Development. J Mol Biol. 2021 Oct 15;433(21):167215.

Franzmann TM and Alberti S. Protein Phase Separation as a Stress Survival Strategy. Cold Spring Harb Perspect Biol. 2019 Jun 3;11(6):a034058.

Gu J, Liu Z, Zhang S, Li Y, Xia W, Wang C, Xiang H, Liu Z, Tan L, Fang Y, Liu C, Li D. Hsp40 proteins phase separate to chaperone the assembly and maintenance of membraneless organelles. Proc Natl Acad Sci U S A. 2020 Dec 8;117(49):31123-31133.

Gu J, Wang C, Hu R, Li Y, Zhang S, Sun Y, Wang Q, Li D, Fang Y, Liu C. Hsp70 chaperones TDP-43 in dynamic, liquid-like phase and prevents it from amyloid aggregation. Cell Res. 2021 Sep;31(9):1024-1027.

Hartl FU. Cellular Homeostasis and Aging. Annu Rev Biochem. 2016 Jun 2;85:1-4.

Hipp MS, Park S, Hartl FU. Proteostasis impairment in protein-misfolding and aggregation diseases. Trends Cell Biol. 2014 Sep;24(9):506-14.

Hou Y, Dan X, Babbar M, Wei Y, Hasselbalch SG, Croteau DL, Bohr VA. Ageing as a risk factor for neurodegenerative disease. Nat Rev Neurol. 2019 Oct;15(10):565-581 
bioRxiv preprint doi: https:/doi org/10.1101/2021.12 17.473198; this version posted December $18,2021$. The copyright holder for this preprint (which was not certified by peer review) is the author/funder, who has granted bioRxiv a license to display the preprint in perpetuity. It is made available under aCC-BY-ND 4.0 International license.

Hsu AL, Murphy CT, Cynthia Kenyon. Regulation of aging and age-related disease by DAF16 and heat-shock factor. Science. 2003 May 16;300(5622):1142-5.

Huang C, Wagner-Valladolid S, Stephens AD, Jung R, Poudel C, Sinnige T, Lechler MC, Schlörit N, Lu M, Laine RF, Michel CH, Vendruscolo M, Kaminski CF, Kaminski Schierle GS, David DC. Intrinsically aggregation-prone proteins form amyloid-like aggregates and contribute to tissue aging in Caenorhabditis elegans. Elife. 2019 May 3;8:e43059.

Klaips CL, Jayaraj GG, Hartl FU. Pathways of cellular proteostasis in aging and disease. J Cell Biol. 2018 Jan 2;217(1):51-63.

Labbadia $\mathrm{J}$ and Morimoto RI. The biology of proteostasis in aging and disease. Annu Rev Biochem. 2015;84:435-64.

Lechler MC, Crawford ED, Groh N, Widmaier K, Jung R, Kirstein J, Trinidad JC, Burlingame AL, David DC. Reduced Insulin/IGF-1 Signaling Restores the Dynamic Properties of Key Stress Granule Proteins during Aging. Cell Rep. 2017 Jan 10;18(2):454-467.

Li D, Liu C. Spatiotemporal dynamic regulation of membraneless organelles by chaperone networks. Trends Cell Biol. 2021 Sep 17;S0962-8924(21)00165-3.

Lu S, Hu J, Aladesuyi B, Goginashvili A, Vazquez-Sanchez S, Diedrich J, Gu J, Blum J, Oung S, Yu H, Ravits J, Liu C, Yates J, Cleveland DW. Heat shock chaperone HSPB1 regulates cytoplasmic TDP-43 phase separation and liquid-to-gel transition. Biorxiv 2021. doi: https://doi.org/10.1101/2021.10.14.464447.

Mateju D, Franzmann TM, Patel A, Kopach A, Boczek EE, Maharana S, Lee HO, Carra S, Hyman AA, Alberti S. An aberrant phase transition of stress granules triggered by misfolded protein and prevented by chaperone function. EMBO J. 2017 Jun 14;36(12):1669-1687.

Mészáros B, Erdős G, Szabó B, Schád É, Tantos Á, Abukhairan R, Horváth T, Murvai N, Kovács OP, Kovács M, Tosatto SCE, Tompa P, Dosztányi Z, Pancsa R. PhaSePro: the database of proteins driving liquid-liquid phase separation. Nucleic Acids Res. 2020 Jan 8;48(D1):D360-D367.

Miller SB, Mogk A, Bukau B. Spatially organized aggregation of misfolded proteins as cellular stress defense strategy. J Mol Biol. 2015 Apr 10;427(7):1564-74.

Mogk A, Bukau B. Role of sHsps in organizing cytosolic protein aggregation and disaggregation. Cell Stress Chaperones. 2017 Jul;22(4):493-502.

Ning W, Guo Y, Lin S, Mei B, Wu Y, Jiang P, Tan X, Zhang W, Chen G, Peng D, Chu L, Xue Y. DrLLPS: a data resource of liquid-liquid phase separation in eukaryotes. Nucleic Acids Res. 2020 Jan 8;48(D1):D288-D295.

Ong JY, Torres JZ. Phase Separation in Cell Division. Mol Cell. 2020 Oct 1;80(1):9-20.

Orti F, Navarro AM, Rabinovich A, Wodak SJ, Marino-Buslje C. Insight into membraneless organelles and their associated proteins: Drivers, Clients and Regulators. Comput Struct Biotechnol J. 2021 Jun 29;19:3964-3977.

Pu YZ, Wan QL, Ding AJ, Luo HR, Wu GS. Quantitative proteomics analysis of Caenorhabditis elegans upon germ cell loss. J Proteomics. 2017 Mar 6;156:85-93. 
bioRxiv preprint doi: https://doi org/10.1101/2021.12 17.473198; this version posted December 18,2021 . The copyright holder for this preprint (which was not certified by peer review) is the author/funder, who has granted bioRxiv a license to display the preprint in perpetuity. It is made available under aCC-BY-ND 4.0 International license.

Putnam A, Cassani M, Smith J, Seydoux G. A gel phase promotes condensation of liquid P granules in Caenorhabditis elegans embryos. Nat Struct Mol Biol. 2019 Mar;26(3):220-226.

Riback JA, Katanski CD, Kear-Scott JL, Pilipenko EV, Rojek AE, Sosnick TR, Drummond DA. Stress-Triggered Phase Separation Is an Adaptive, Evolutionarily Tuned Response. Cell. 2017 Mar 9;168(6):1028-1040.e19.

Ross CA and Poirier MA. Protein aggregation and neurodegenerative disease. Nat Med. 2004 Jul;10 Suppl:S10-7.

Saad S, Cereghetti G, Feng Y, Picotti P, Peter M, Dechant R. Reversible protein aggregation is a protective mechanism to ensure cell cycle restart after stress. Nat Cell Biol. 2017 Oct;19(10):1202-1213.

Shin $\mathrm{Y}$ and Brangwynne CP. Liquid phase condensation in cell physiology and disease. Science. 2017 Sep 22;357(6357):eaaf4382.

Skuodas S, Clemons A, Hayes M, Goll A, Zora B, Weeks DL, Phillips BT, Fassler JS. The ABCF gene family facilitates disaggregation during animal development. Mol Biol Cell. 2020 Jun 15;31(13):1324-1345.

Soto C, Pritzkow S. Protein misfolding, aggregation, and conformational strains in neurodegenerative diseases. Nat Neurosci. 2018 Oct;21(10):1332-1340.

Turner BE, Basecke SM, Bazan GC, Dodge ES, Haire CM, Heussman DJ, Johnson CL, Mukai CK, Naccarati AM, Norton SJ, Sato JR, Talavera CO, Wade MV, Hillers KJ. Proteomic identification of germline proteins in Caenorhabditis elegans. Worm. 2015 Feb 9;4(1):e1008903.

Tyanova S, Temu T, Sinitcyn P, Carlson A, Hein MY, Geiger T, Mann M, Cox J. The Perseus computational platform for comprehensive analysis of (prote)omics data. Nat Methods. 2016 Sep;13(9):731-40.

Ungelenk S, Moayed F, Ho CT, GrousI T, Scharf A, Mashaghi A, Tans S, Mayer MP, Mogk A, Bukau B. Small heat shock proteins sequester misfolding proteins in near-native conformation for cellular protection and efficient refolding. Nat Commun. 2016 Nov 30;7:13673.

Updike DL, Knutson AK, Egelhofer TA, Campbell AC, Strome S. Germ-granule components prevent somatic development in the C. elegans germline. Curr Biol. 2014 May 5;24(9):970-5.

Vecchi G, Sormanni P, Mannini B, Vandelli A, Tartaglia GG, Dobson CM, Hartl FU, Vendruscolo $M$. Proteome-wide observation of the phenomenon of life on the edge of solubility. Proc Natl Acad Sci U S A. 2020 Jan 14;117(2):1015-1020.

Venz R, Pekec T, Katic I, Ciosk R, Yvès Ewald CY. End-of-life targeted degradation of DAF2 insulin/IGF-1 receptor promotes longevity free from growth-related pathologies. Elife. 2021 Sep 10;10:e71335.

Verma K, Verma M, Chaphalkar A, Chakraborty K. Recent advances in understanding the role of proteostasis. Fac Rev. 2021 Sep 15;10:72.

Wallace EW, Kear-Scott JL, Pilipenko EV, Schwartz MH, Laskowski PR, Rojek AE, Katanski CD, Riback JA, Dion MF, Franks AM, Airoldi EM, Pan T, Budnik BA, Drummond DA. Reversible, Specific, Active Aggregates of Endogenous Proteins Assemble upon Heat Stress. Cell. 2015 Sep 10;162(6):1286-98. 
Walther DM, Kasturi P, Zheng M, Pinkert S, Vecchi G, Ciryam P, Morimoto RI, Dobson CM, Vendruscolo M, Mann M, Hartl FU. Widespread Proteome Remodeling and Aggregation in Aging C. elegans. Cell. 2015;161(4):919-32.

Wickham H (2016). ggplot2: Elegant Graphics for Data Analysis. Springer-Verlag New York. ISBN 978-3-319-24277-4, https://ggplot2.tidyverse.org.

Wiegand T, Hyman AA. Drops and fibers - how biomolecular condensates and cytoskeletal filaments influence each other. Emerg Top Life Sci. 2020 Dec 11;4(3):247-261.

You K, Huang Q, Yu C, Shen B, Sevilla C, Shi M, Hermjakob H, Chen Y, Li T. PhaSepDB: a database of liquid-liquid phase separation related proteins. Nucleic Acids Res. 2020 Jan 8;48(D1):D354-D359.

Zhou Y, Zhou B, Pache L, Chang M, Khodabakhshi AH, Tanaseichuk O, Benner C, Chanda SK. Metascape provides a biologist-oriented resource for the analysis of systems-level datasets. Nat Commun. 2019 Apr 3;10(1):1523. 


\section{FIGURE LEGENDS}

\section{Figure 1. Functional annotation of MLO associated proteins}

(A-B) Enriched gene ontology [GO] clusters of biological processes [BP] and cellular components [CC] of MLO associated proteins respectively (413 entries, Dataset from MLOSMetaDb). (C) Protein-Protein Interaction networks of MLO associated proteins.

\section{Figure 2. MLO associated proteins behaviour during aging}

(A-B) Histograms showing the distribution of proteins in total proteome $(A)$ and aggregate or insoluble proteome $(B)$ identified during aging of $C$. elegans. Blue denotes the total number of proteins and red denotes the MLO associated proteins (364 entries).

(C-D) Heat map showing the age and strain dependent z-score normalized LFQ intensity changes of MLO associated proteins in the total proteome $(C)$ and aggregate or insoluble proteome (D).

(E) Volcano plot showing the distribution of abundance levels of proteins between day1 and day12 of wildtype worms. (F) Scatter plot showing distribution of the same insoluble proteins in day12 wildtype and daf-2 mutant worms (270 common entries, Pearson correlation coefficient 0.91 ). (G) Enriched gene ontology clusters of biological process of significantly upregulated MLO-APs in aggregate during aging.

\section{Figure 3. Age and strain dependent functional annotation of MLO associated proteins}

(A) Enriched biological process of the common MLO associated proteins that have been quantified in all time points in total and aggregate proteome of wildtype and daf-2 mutant worms during aging.

(B) Enriched cellular components of the common MLO associated proteins that have been quantified in all time points in total and aggregate proteome of wildtype and daf-2 mutant worms during aging.

Figure 4. Relative abundance of MLO associated proteins involved in embryonic development and cell cycle (mitotic and meiotic)

Box plots showing age and strain specific abundance changes (relative to day1) of proteins identified in total and aggregate proteomes. (A-B) Proteins involved in embryonic development (37 entries). (C-D) Proteins involved in mitotic cell division (35 entries). (E-F) Proteins involved in meitotic cell division (24 entries). 


\section{Figure 5. Relative abundance of MLO associated proteostasis components}

Box plots showing age and strain specific abundance changes (relative to day1) of proteins identified in total and aggregate proteomes. (A-B) Proteostasis components excluding cytosolic HSPs HSP-70s and sHSPs (64 entries). (C-D) Cytosolic HSPs (HSP-70s and sHSPs 13 entries). 
bioRxiv preprint doi: https://doi.org/10.1101/2021.12.17.473198; this version posted December 18, 2021. The copyright holder for this preprint (which was not certified by peer review) is the author/funder, who has granted bioRxiv a license to display the preprint in perpetuity. It is made available under aCC-BY-ND 4.0 International license.

\section{FIGURES}


bioRxiv preprint doi: https://doi org/10.1101/2021.12.17.473198; this version posted December 18, 2021. The copyright holder for this preprint (which was not certified by peer review) is the author/funder, who has granted bioRxiv a license to display the preprint in

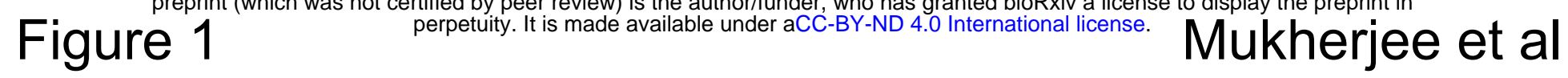
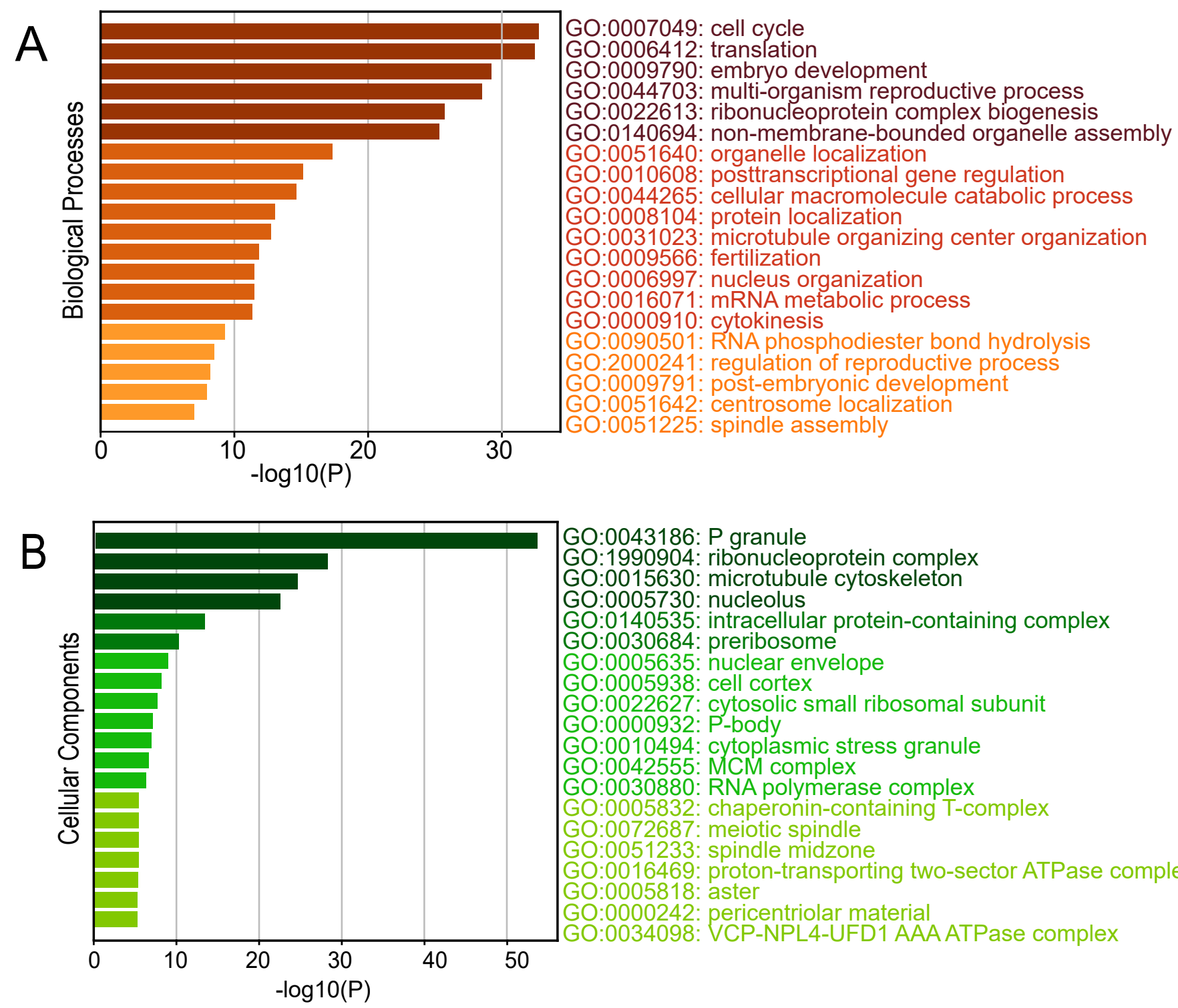

GO:0043186: P granule GO:1990904: ribonucleoprotein complex GO:0015630: microtubule cytoskeleton GO:0005730: nucleolus GO:0140535: intracellular protein-containing complex GO:0030684: preribosome

GO:0005635: nuclear envelope GO:0005938: cell cortex

GO:0022627: cytosolic small ribosomal subunit GO:0000932: P-body GO:0010494: cytoplasmic stress granule GO:0042555: MCM complex

GO:0030880: RNA polymerase complex GO:0005832: chaperonin-containing T-complex GO:0072687: meiotic spindle GO:0051233: spindle midzone GO:0016469: proton-transporting two-sector ATPase complex GO:0005818: aster GO:0000242: pericentriolar material GO:0034098: VCP-NPL4-UFD1 AAAATPase complex
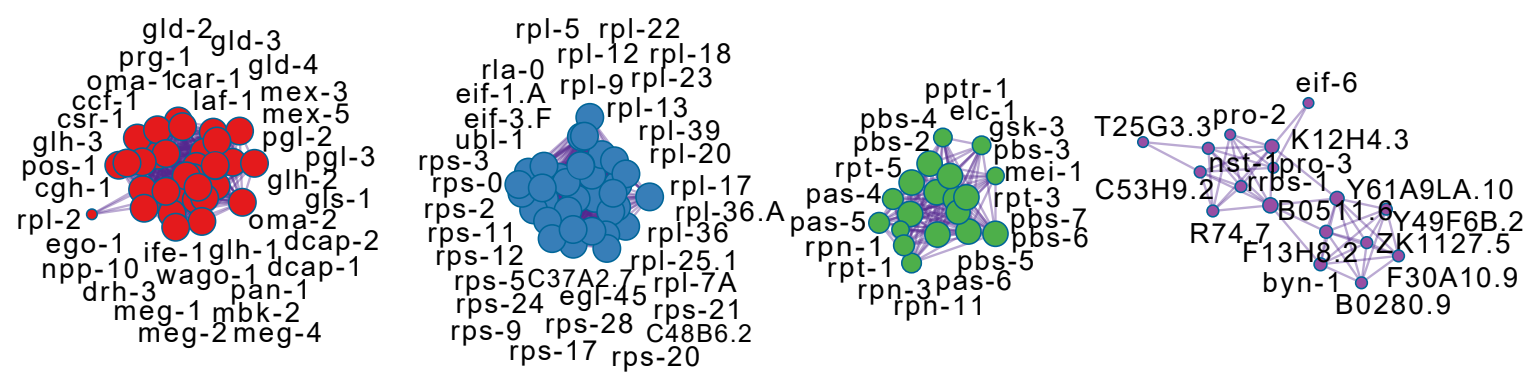

$$
\left\{\begin{array}{l}
\text { dnc-2 dyci-1 } \\
\text { copd-1 } \\
n p p-20 \\
\text { npp-2 } \\
n p p-4
\end{array}\right.
$$

$$
\underbrace{\text { ran-1 exos-3 }}_{\text {ima-3 }}
$$$$
\text { let-716 }{ }_{\text {nifk-1 }}
$$$$
\text { ruvb-2 }
$$$$
\text { snr-2 } \mathrm{rbm}_{-34}^{\mathrm{H} 06104.3}
$$$$
\text { let-858 prp-8 }
$$
$48 \mathrm{~B} 6 \mathrm{~A}$.

$$
\begin{aligned}
& 04.3 \text { ruvb-1 } \\
& \text { ohis-9 } \\
& \text { ubc-9 } \\
& \text { uba-2 let-70 oufd-1 } \\
& \text { smo-1 }
\end{aligned}
$$

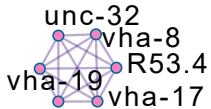
ha-19 R53.4 vha-2

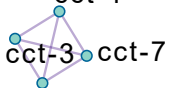
cct-2

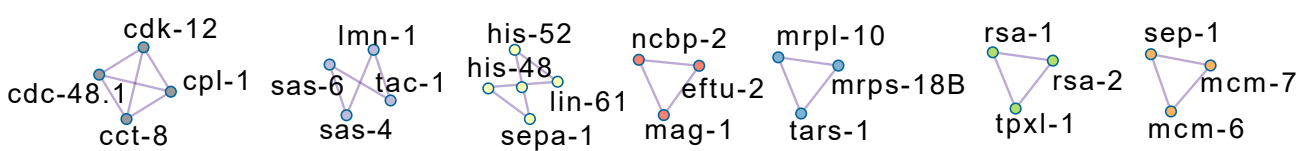
cct-8 sås-4 sepa-1 mag-1 $_{\text {tars-1 }}^{\circ}$ mrps-18B $\mathrm{tpxl}_{\mathrm{mcm}-6}^{\mathrm{rsa}-2} \mathrm{mcm}-7$ 
bioRxiv preprint doi: https://doi org/10.1101/2021.12.17 473198; this version posted December 18, 2021. The copyright holder for this

preprint (which was not certified by peer review) is the author/funder, who has granted bioRxiv a license to display the preprint in

Figure 2 perpetuity. It is made available under aCC-BY-ND 4.0 International license.Mukherjee et al

A
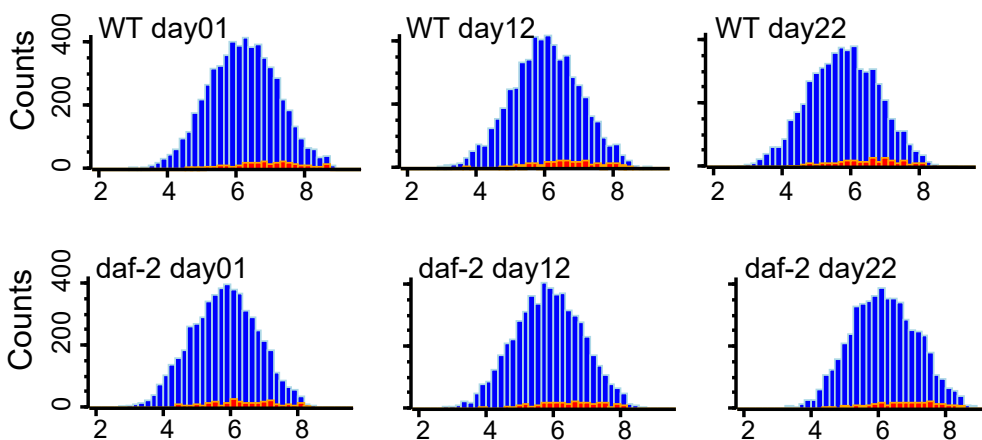

B

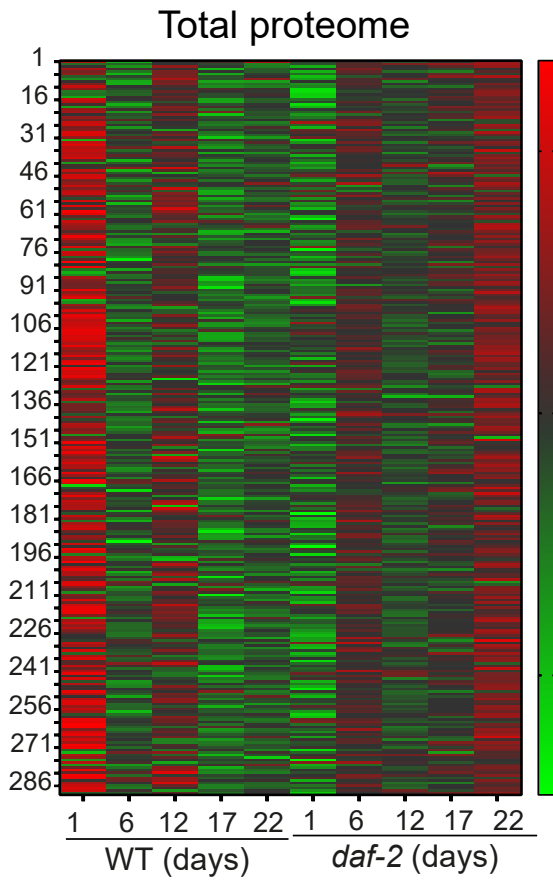

$\mathrm{F}$

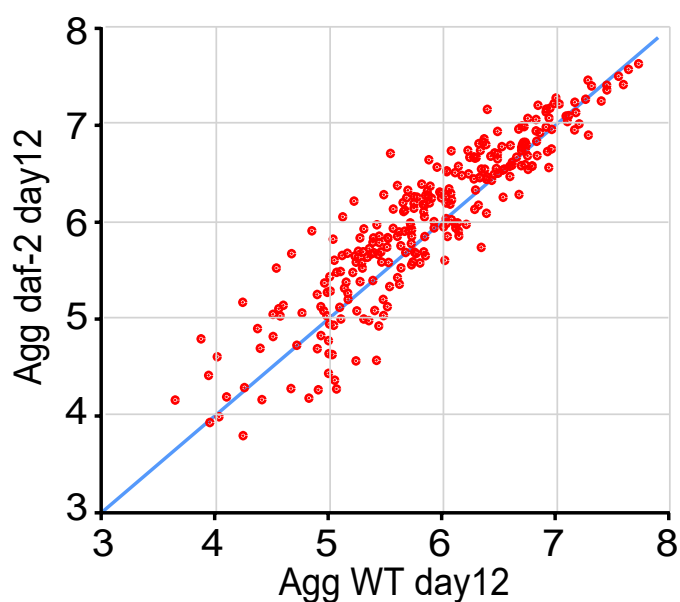

G

Agg WT day12
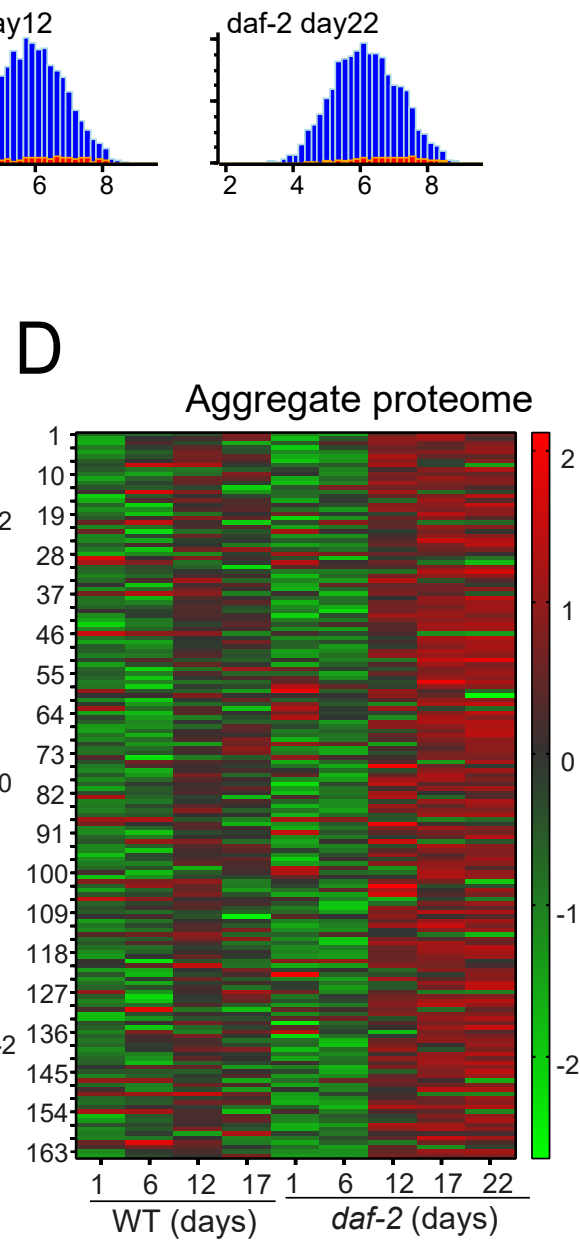
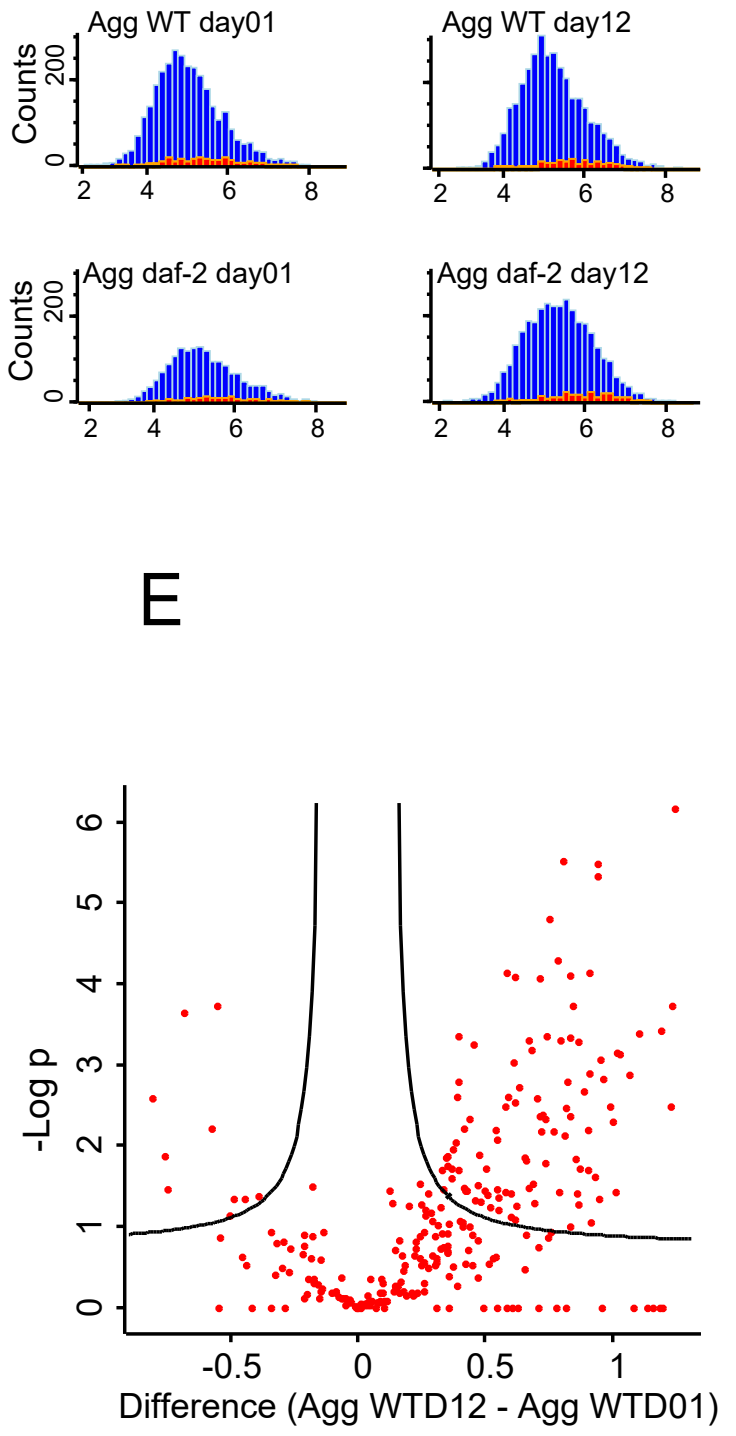

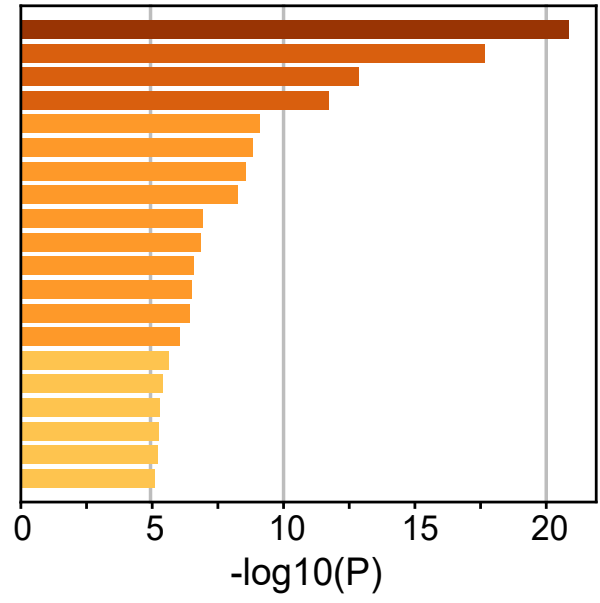

GO:0007049: cell cycle

G:0007276: gamete generation

GO:0009790: embryo development

:0051246: rocess GO:0051246: regulation of

G:0000910. Cytokinesis GO:0044265: cellular macrom GO:0006260: DNA replication GO:0051640: organelle localization G:0070727: cellular macromolecule localization :0031023: microtubule organizing center organization O:0140694: non-membrane-bounded organelle assembly O:0048469: cell maturation

GO:0000212: meiotic spindle organization

GO:0006418: tRNA aminoacylation for protein translation 
A

GO Biological Processes

tRNA aminoacylation for protein translation translation stress granule assembly spindle disassembly RNA phosphodiester bond hydrolysis ribonucleoprotein complex biogenesis regulation of translation regulation of reproductive process regulation of protein metabolic process regulation of cell cycle protein localization posttranscriptional regulation of gene expression post-embryonic development positive regulation of reproductive process positive regulation of gene expression organelle localization nucleus organization

non-membrane-bounded organelle assembly multi-organism reproductive process mRNA metabolic process mitotic nuclear division microtubule organizing center organization meiotic spindle organization

establishment of organelle localization establishment of localization in cell ER-associated misfolded protein catabolic process embryo development ending in birth or egg hatching embryo development

DNA unwinding involved in DNA replication determination of adult lifespan cytoplasmic translation cytokinesis

centrosome localization cellular process involved in reproduction cellular macromolecule localization cellular macromolecule catabolic process cell maturation

$$
\text { cell cycle }
$$

anterior/posterior pattern specification

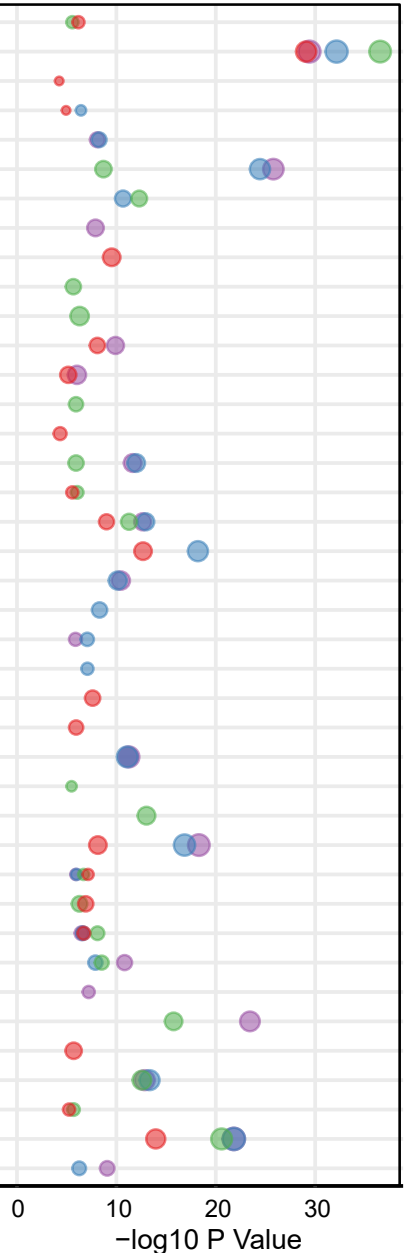

B

VCP-NPL4-UFD1 AAA ATPase complex supramolecular complex spindle midzone spindle microtubule RNA polymerase complex ribonucleoprotein complex replisome proton-transporting two-sector ATPase complex protein phosphatase type $2 \mathrm{~A}$ complex proteasome regulatory particle proteasome core complex proteasome complex preribosome, large subunit precursor preribosome

pericentriolar material P-body

nuclear replication fork nuclear protein-containing complex nuclear lumen nuclear envelope mitotic spindle

microtubule cytoskeleton microtubule associated complex messenger ribonucleoprotein complex MCM complex intracellular protein-containing complex intermediate filament cytosolic small ribosomal subunit cytosolic ribosome

cytoplasmic stress granule chaperonin-containing $\mathrm{T}$-complex catalytic complex

\begin{tabular}{|c|l|}
\hline Count & Color \\
\hline 20 & daf-2 aggregate \\
40 & daf-2 total \\
60 & WT aggregate \\
& WT total \\
\hline
\end{tabular}

\section{GO Cellular Component}

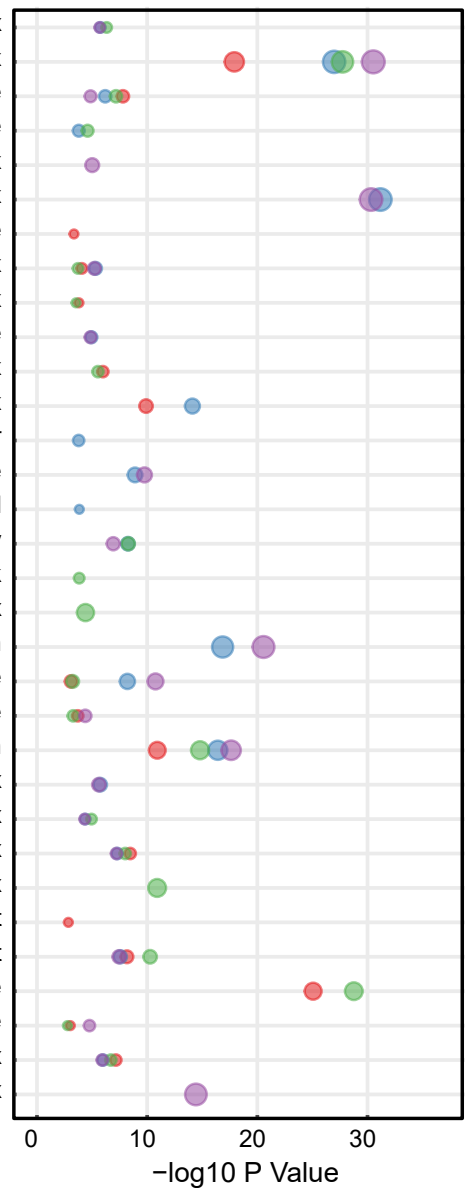


A

Developmental proteins in total

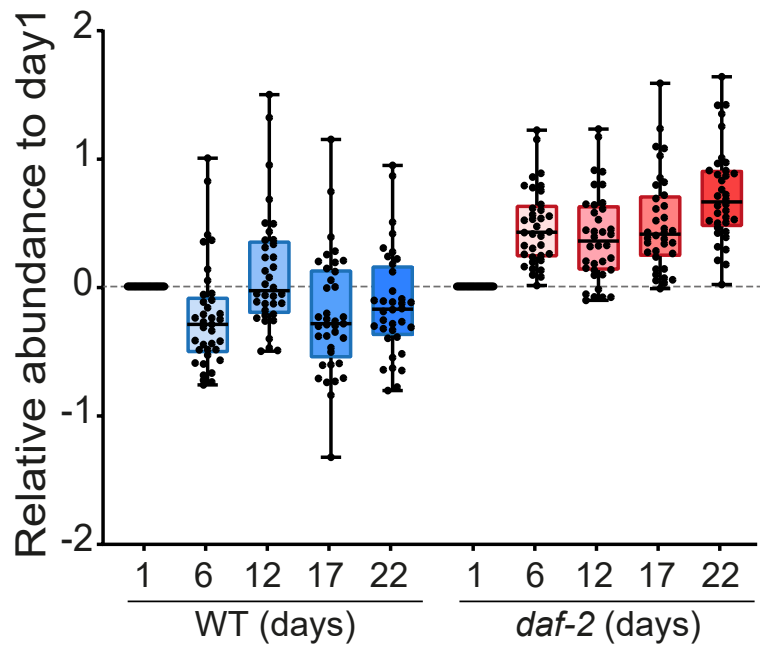

C

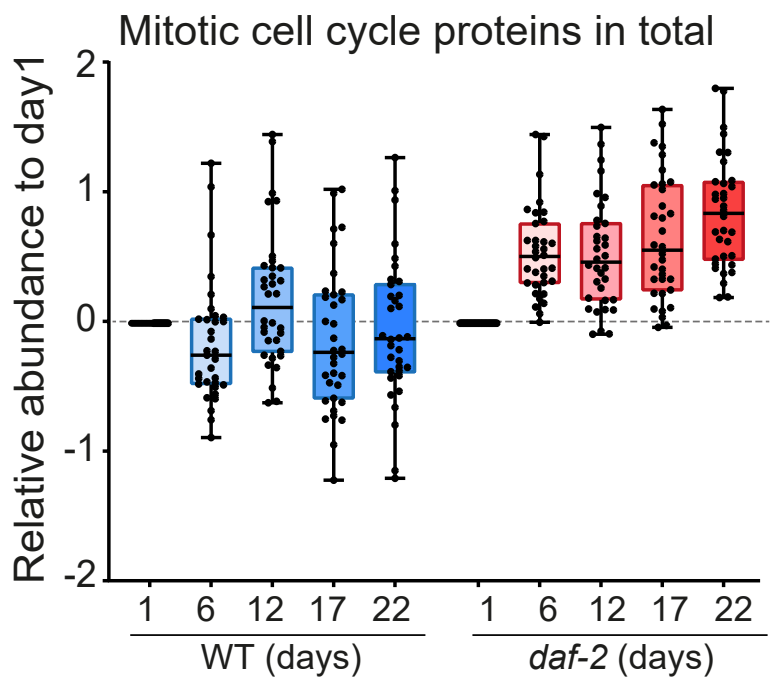

E Meiotic cell cycle proteins in total

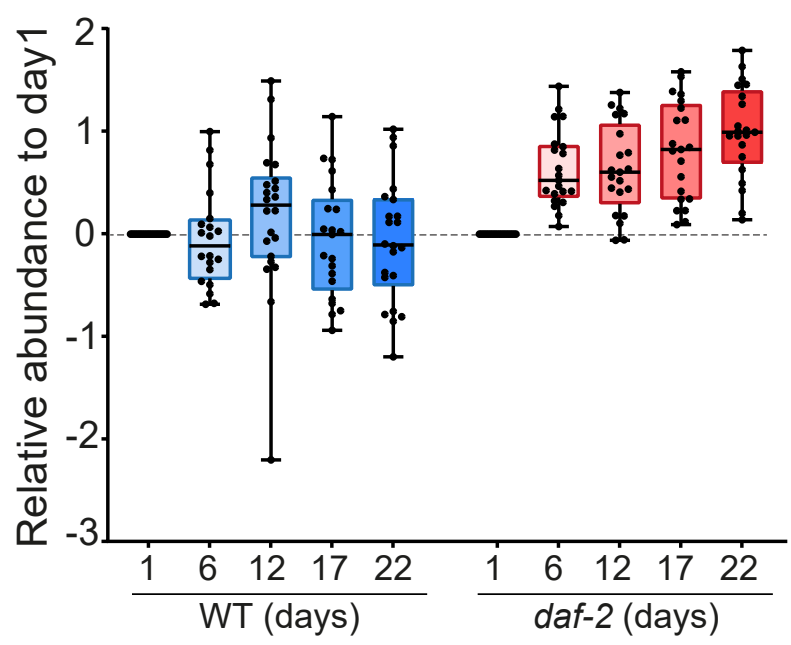

B

Developmental proteins in aggregates

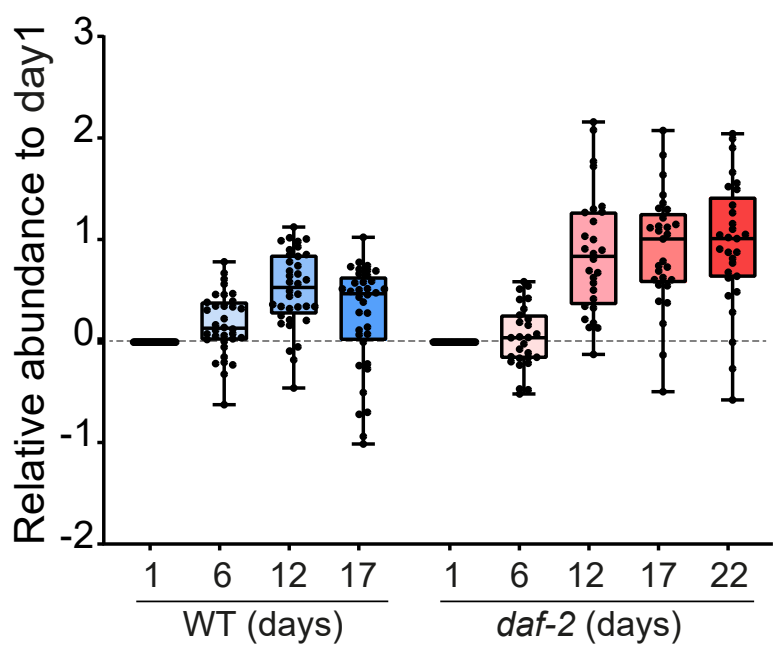

$\mathrm{D}$

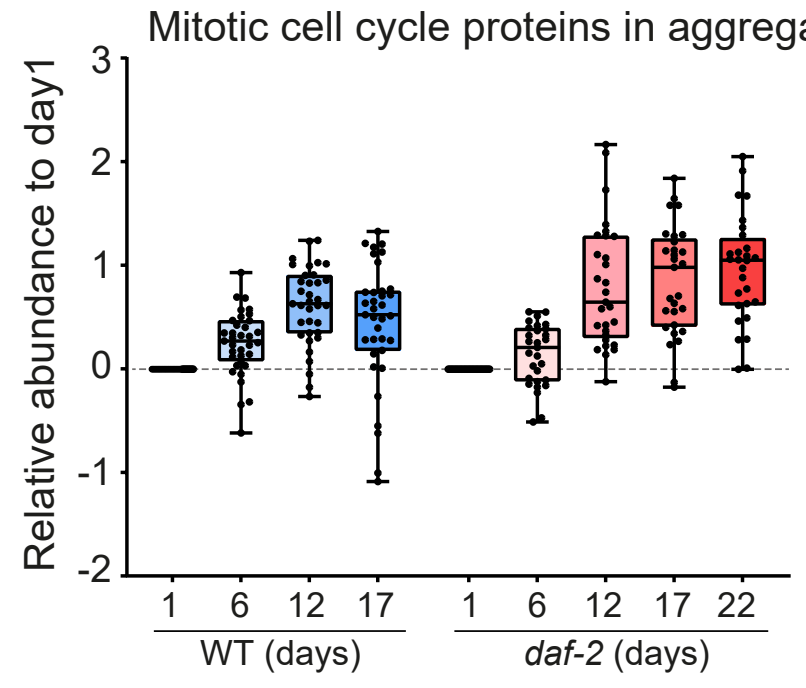

$\mathrm{F}$ Meiotic cell cycle proteins in aggregate

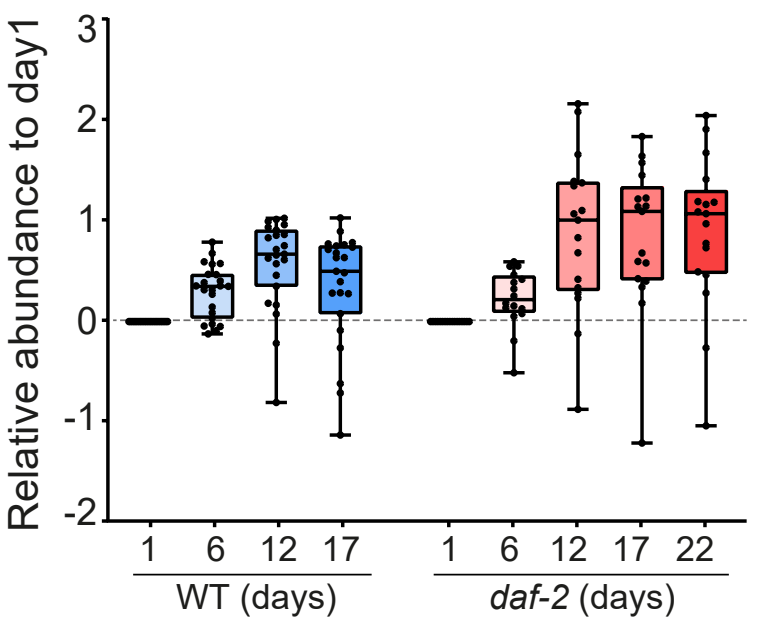


A

Proteostasis components in total

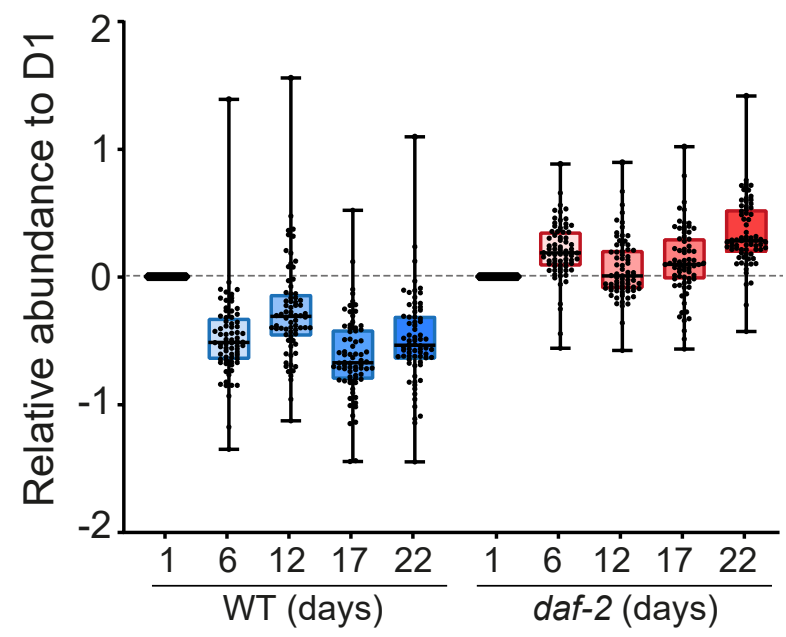

HSPs in total

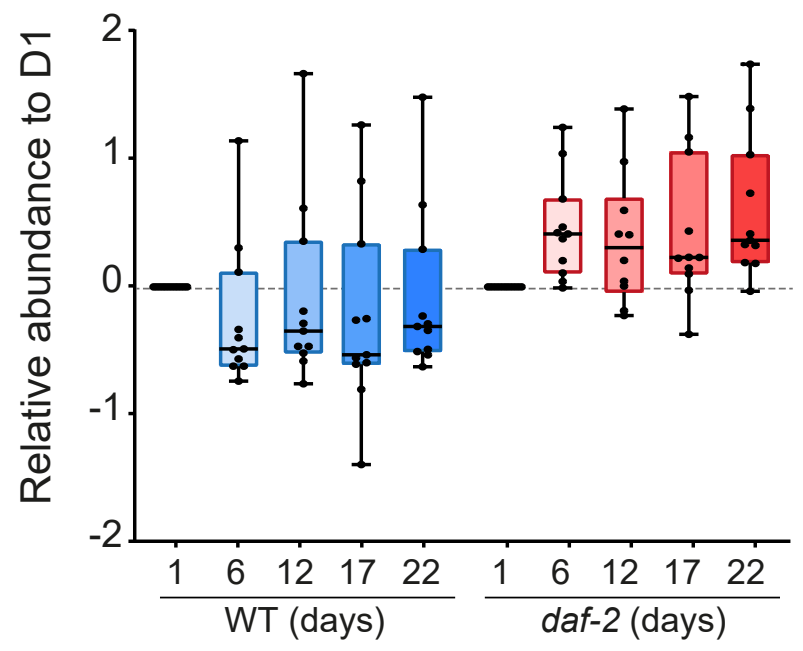

$\mathrm{B}$

Proteostasis components in aggregates

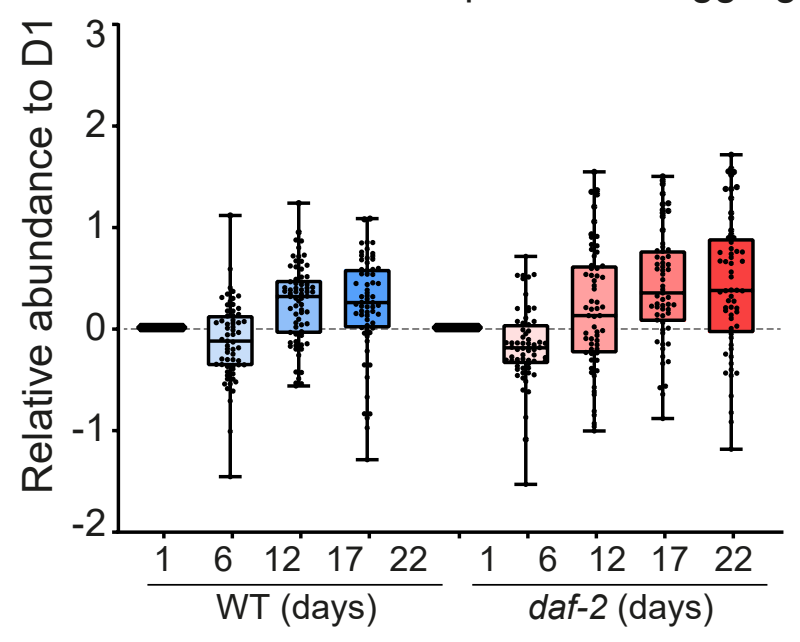

D

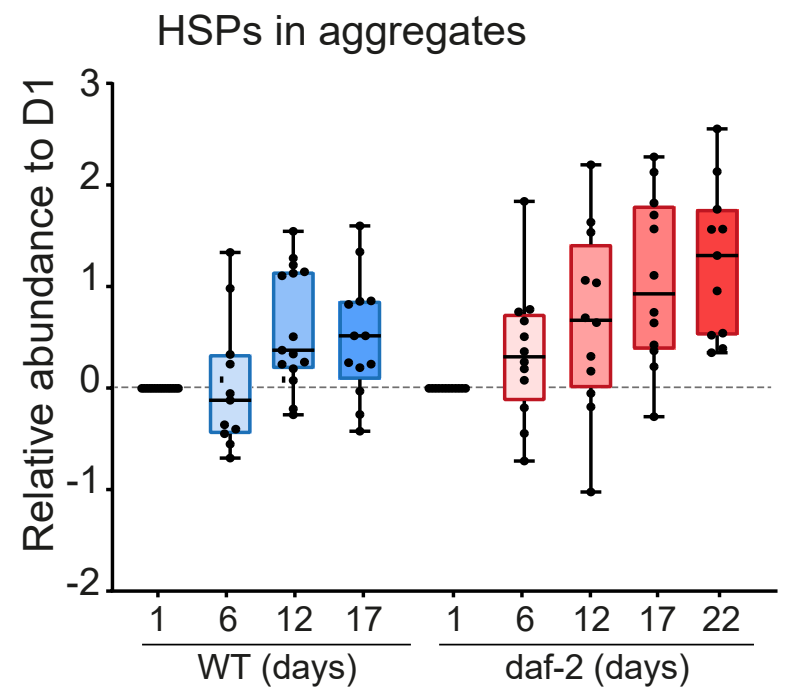

